\title{
AN ANALYSIS OF EFL COLLEGE LEVEL LEARNER'S WRITING COMPETENCE IN WRITING AN ARGUMENTATIVE ESSAY
}

\author{
Desi Surlitasari Dewi \\ English Department, Teacher Training and Education Faculty, University of Riau Kepulauan, Batam, \\ Indonesia \\ Email:desi@unrika.ac.id
}

\begin{abstract}
One of student's competence that is expected in college level is to be able to write an argumentative essay. An argumentative essay is a genre of writing that requires students to investigate a topic; collect; generate, evaluate evidence, and establish a position on the topic in a concise manner. The purpose of this study was to find out how EFL learners' writing competence in writing an argumentative essay. Then, the research question was how are EFL learners' writing skill in writing an argumentative essay. The research was a descriptive qualitative study, as the data of EFL learners' writing was analyzed to determine their competence of writing an argumentative essay. The analysis was conducted by describing and explaining the data. The study found that EFL learners' writing skill in writing an argumentative essay was mostly adequate. In general, the organization was clear and showed the purpose of writing clearly; the content was in logical sequence; the grammar was mostly effective, even though, there were some flaws in the structure of some complex sentences; most of the mechanics was legible and neat, sometimes the word choice are not too appropriate for the context, but it could convey the message of an essay.
\end{abstract}

Keywords : Writing Skill, Argumentative essay.

\section{INTRODUCTION}

It is considered that one of the most crucial skills for academic and career success for EFL learners, as evident in surveys of stakeholders from higher education and the workforce, is mastering the art of written communication as described by Sparks, et al (2014, p. 1). Writing is important to be integrated with other language skills, in particularly stressed, in the belief that this leads to more effective language learning and it provides more natural contexts for writing activities. It is one of the skills in English which must be mastered by EFL learners at teaching English as foreign language. In spite of that, there are many EFL learners thought that writing is a difficult activity than the other foreign language skill.

In teaching English as foreign language, writing has a fundamental role as it is used to measure someone's ability to deliver the message in written form. In this study, the focus is writing an essay, especially an argumentative essay. As Hasani (2016, p. 2) argued that argumentative writing is considered as a critical skill to be learned for college level 
learners. An argumentative essay is one of writing material taught by the teacher to analyze EFL learners' writing skill in writing an essay. The writer knows the problems encountered by the EFL learners in writing an argumentative essay.

Provision of English subject in teaching English as foreign language has been intended to make EFL learners able to develop the competence to write and communicate in spoken and written in advanced level. The EFL learners' are also expected to reach the level of knowledge that they are able to make an information or text with the ability to write as well as activating their logical reasoning of a problem.

Thus, teacher should teach writing well so that EFL learners are able to receive and give precise and correct information in the written form. As writing skill becomes very important in education, EFL learners should be able to perform and train themselves to have a good writing. On the other hand, the government expects the EFL learners can achieve the target of curriculum. However, in facts, some of the EFL learners at teaching English as foreign language are struggling to comprehend the writing competence written in syllabus.

Many components or skills are involved in writing task. These aspects of the writing skills include (1) writing mechanics like grammar, sentence structure, spelling and punctuation, (2) planning a writing strategy, (3) communicating ideas clearly and concisely, (4) constructing reasoned demonstrable argument and (5) organizing ideas effectively.

Based on the research done previously in four language skills, the learners tend to state that the most difficult skill to be learned is writing. There are some difficulties faced by EFL learners in writing class. First, they do not have idea to write. Second, they are still confused in organizing the writing. Third, they often do some mistakes with the lack of knowledge in vocabularies, the grammatical structure, especially in writing activities. Fourth, they are struggling to pick the appropriate word choice to deliver the message.

Purdue (2018) mentions that an argumentative essay is a genre of writing in which the writer has to investigate the topic, find the appropriate evidence by collecting, generating, and evaluating the data, and show the stance about the topic in a concise manner. Argumentative essay assignments generally call for extensive research or literature or previously published material. The rules for an argumentative essay are the following:

a. A clear, unambigous, and defined thesis statement

b. It should have three main parts, introduction; body; and conclusion

c. Evidence or supporting details must be included in body paragraph 
d. Evidential supporting details could be actual, logical, or statistical evidence.

e. The conclusion should be able to make a restatement of the supporting details, it is not simply a conclusion.

According to Nilson $(1984$, p.8) writing is a skill which has been developed in civilized society to pass on knowledge or messages. Some experts usually define it by looking at its characteristics. One of writing characteristics is related to speaking. Tidyman (1959, p.257) says that writing is closely related to speaking, not only in such items as content, organization of ideas, and vocabulary, but also in the use of pauses and the modulation of the voice to show the division and the relationship of ideas.

While the other characteristic is said by Nilson (1984, p.134), he says that writing is not something which is natural to humans. It is the most complex skill to be developed. In addition, Tidyman (1959, p.66) says that the important thing in writing is attitudewillingness to write. Furthermore, Hedge (2002, p.134) says that writing as one of the language skills has given an important contribution to human.

According to Harmer (2007, p.86) writing is a process and that what is written is often heavily influenced by the constraints of genres, then these elements have to be present in learning activities. Writing is the presentation of language in a textual medium through the use of a set of sign or symbols (known as a writing system). On the other hand, Crystal (2003, p.98) mentioned that writing is multifaceted, it is only logical that it evokes different images. He also stated that writing is a combination of process and product. The process refers to the act of gathering ideas and working with them until they are presented in a manner that is polished and comprehensible to readers. Writing is a form of our thinking, ideas, opinion, imagination, wish and feeling that poured in a paper and hope other know about them by reading the creation. In writing, the aspects of writing include the use of vocabulary, structure of the sentence, composition of the sentence, spelling and punctuation. These aspects are important to master in order to able to produce a good writing.

In general, there are four steps of writing according to Linse (2003, p.105), they are:

\section{a. Prewriting}

For every piece of writing, there is always a pre writing activity. Before writing, the writer should let the minds explore the topic possibility.. 
Then, record the ideas to visualize the imagination on a piece of paper. State the purpose and choose the subject which is known to the writer is important to do carefully. Communication, in written or spoken form, will always have the similar purpose which is to persuade, entertain or to influence the reader.

\section{b. Writing}

Before the writing started, defining the topic is the first step in writing. Writing is started based on the topic and no need to worry about making the mistakes because it is possible to change the idea and words later anyway. After brainstorming the ideas and subject, someone should write whatever they thought in their minds and it is not necessary to worry about the mistake made in structure, spelling, vocabulary, grammar and punctuationas they will have time to revise and edit their writing.

\section{c. Revising and Editing}

Reread and edit the writing to revise the mistakes. Revising is the most important steps in writing. It aims to improve the writing you have made and measure how well the idea stated. Revising can be liked rearranging ideas, developing ideas further any idea that do not fit to the topic. After revising the idea, the writing can be edited carefully. It focuses on structure, grammar word choices, spelling and punctuation.

\section{d. Publishing}

After a piece of writing has been edited, it is ready to be published. Publishing refers to putting the writing in a final finished format where it can be shared with others.

Meanwhile, Brown (2007) mentioned that there are five elements, which are the indicators of writing. They are:

1. Organization: introduction, body, and conclusion

2. Logical development of idea: Content

3. Grammar

4. Punctuation spelling and mechanics

5. Style and quality of expression

Baker, Brizee, Angeli (2013) mentions that an argumentative essay is a genre of writing in which the writer has to investigate the topic, find the appropriate evidence by collecting, generating, and evaluating the data, and show the stance about 
the topic in a concise manner. Argumentative essay assignments generally call for extensive research or literature or previously published material. The rules for an argumentative essay are the following:

a. A clear, unambigous, and defined thesis statement

b. It should have three main parts, introduction; body; and conclusion

c. Evidence or supporting details must be included in body paragraph

d. Evidential supporting details could be actual, logical, or statistical evidence.

e. The conclusion should be able to make a restatement of the supporting details, it is not simply a conclusion.

\section{RESEARCH METHODOLOGY}

According to Creswell (2003, p.18) research design divided into three, they are quantitative, qualitative, and mixed research design. This study was conducted in descriptive qualitative research design as the data was analyzed and explained thoroughly, although statistical data was used to help the description of the data. Statistical description will be used to generate the result of the research and help to describe the result. He also said the word qualitative implies and emphasis on processes and meaning that are not rigorously examined or measured (if it measured at all), in terms of quantity, amount, intensity or frequency. According to Railis (1998) in Creswell (2003, p.181) these are characteristics of qualitative research:

a. Qualitative research takes places in the natural setting. The qualitative research often goes to the site of the participant to conduct the research.

b. Qualitative research uses multiple methods are interactive and humanistic. The methods of data collection are rowing and they increasingly involve active participants and sensitivity of the participants and sensitivity to the participant in the study.

c. Qualitative research is emergent rather than tightly refigured. Several aspect emerge during a qualitative study.

d. Qualitative research is fundamentally interpretive; this means that the researcher makes an interpretation of the data.

e. The qualitative researcher views social phenomena holistically. This explains why qualitative research studies appear as broad. 
f. The qualitative researcher adopts and uses one or more strategies inquiry as a guide for the procedures in the qualitative study. For beginning researcher it is enough to use only one strategy and to look in recent procedural books for guidance as how to design a proposal and conduct the procedures of the strategy. The data in this study are described by analyzing EFL learners writing skill in writing an argumentative essay. The writer gave the writing test to collect the data. Writing test for this test is an instruction to create an argumentative essay. The administration of the writing task uses structure to write an argumentative essay. Finally, researcher analyzed the data by using analytical scoring designed by Brown and Bailey (1984) in Brown (2004).

\section{RESULTS}

The writing scores of EFL learners in this study were determined by using analytic scale for rating composition tasks by Brown and Bailey (1984, pp.39-41). The following figures indicate the data of EFL learners' writing skills gathered from the test.

a. Organization

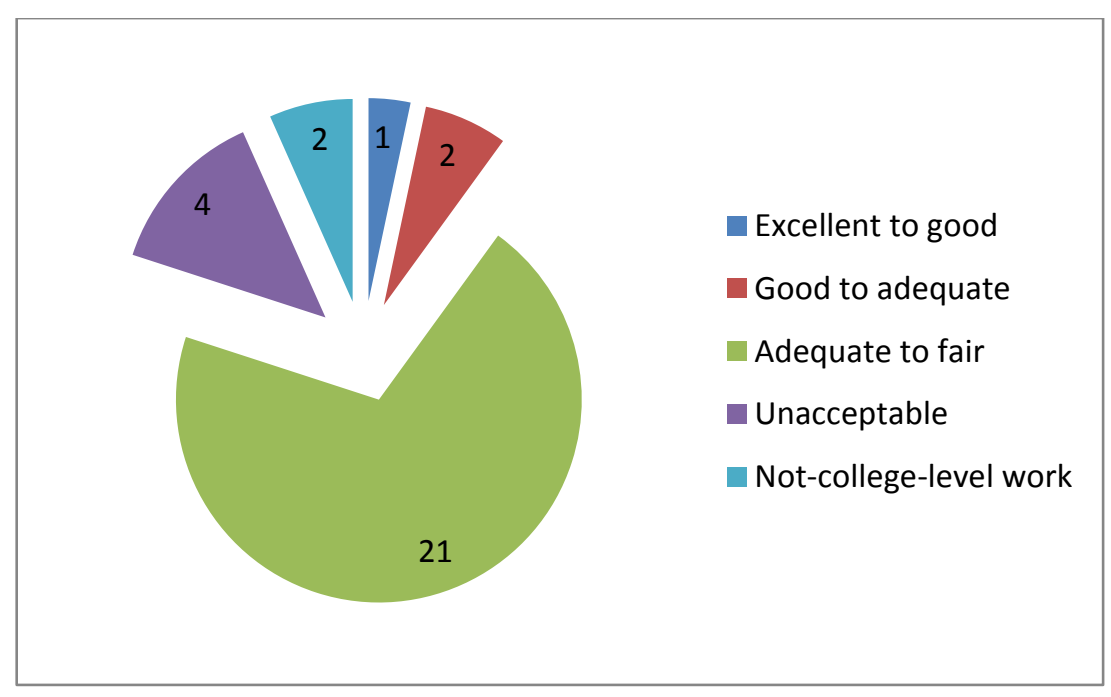


b. Logical development of ideas

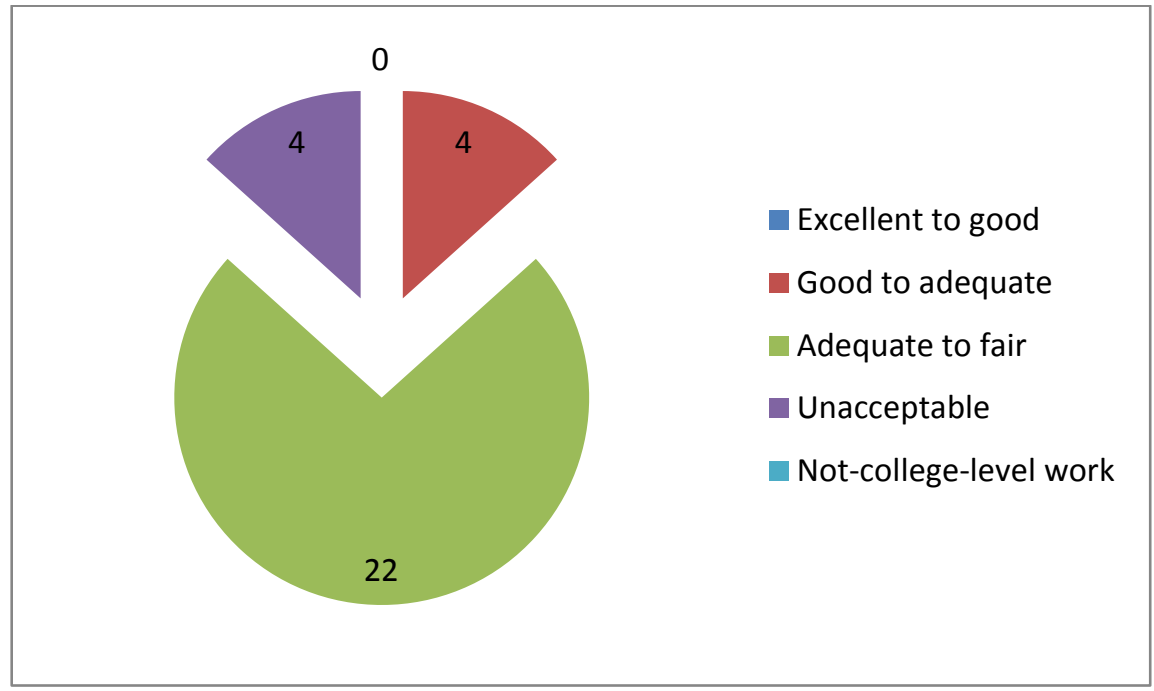

c. Grammar

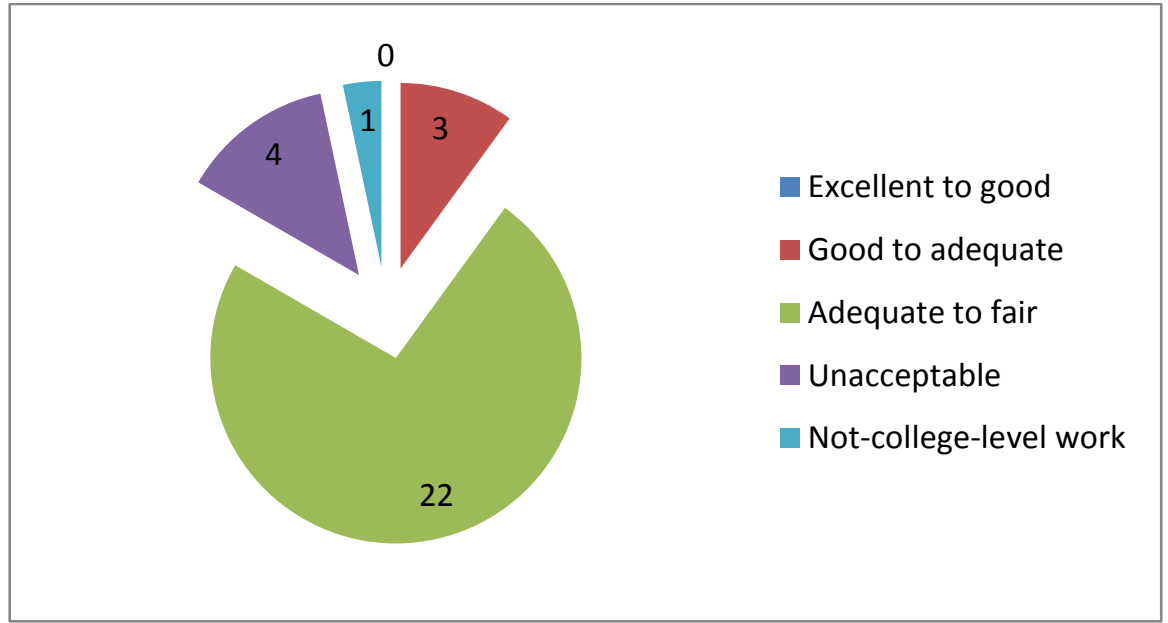

d. Punctuation, spelling, and mechanics

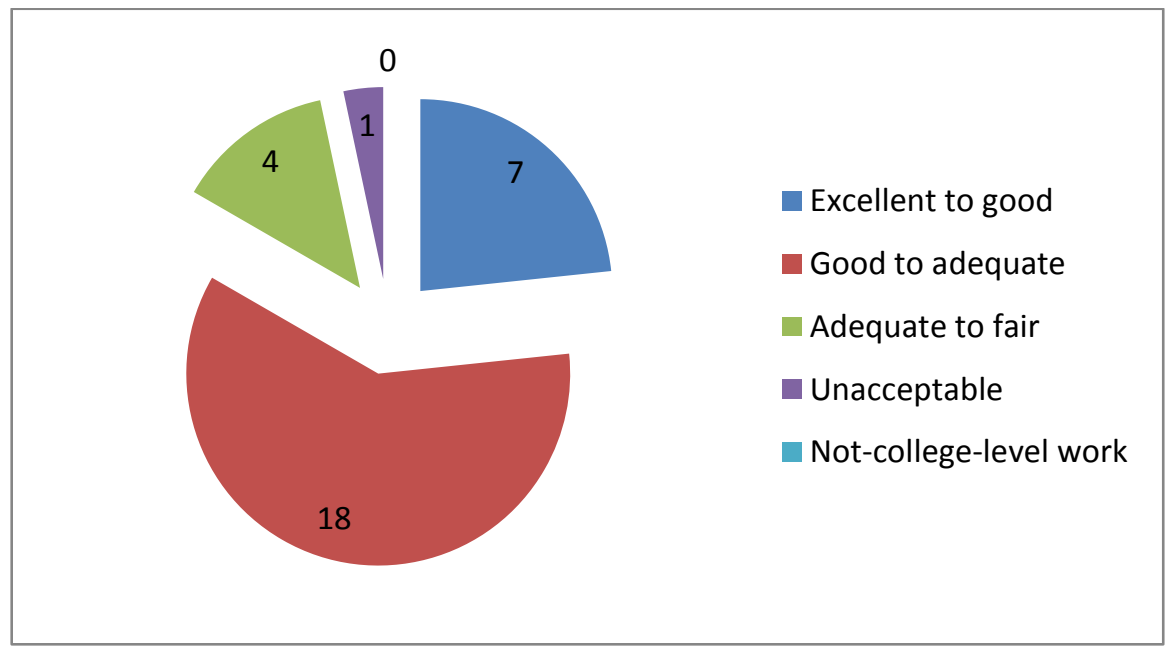


e. Style, quality, and expression

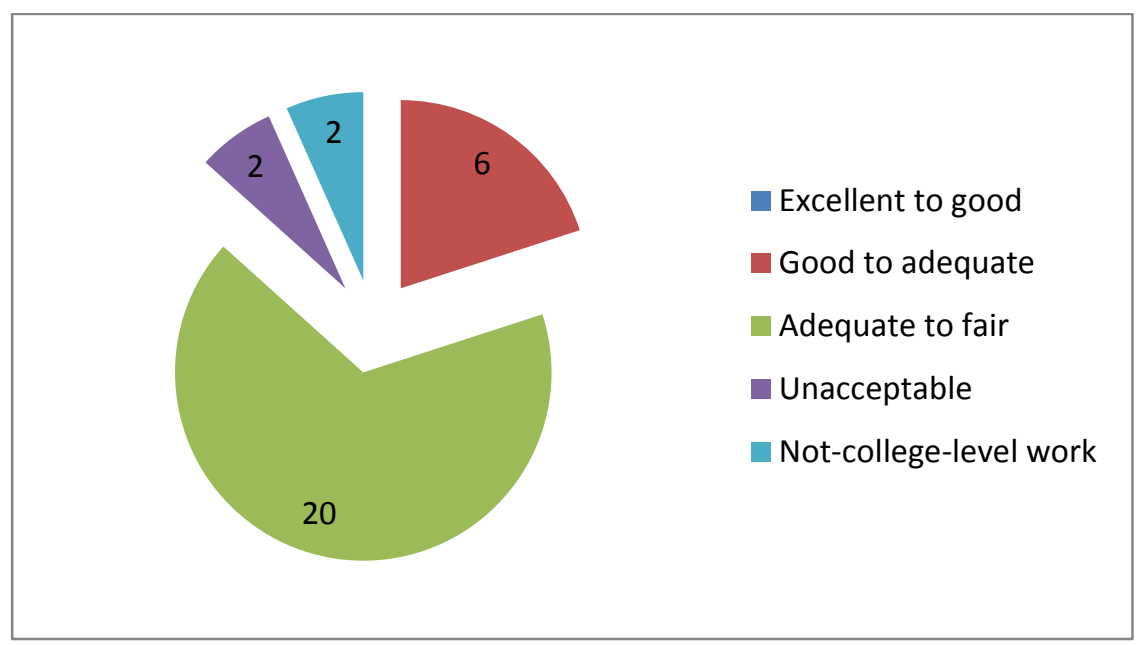

\section{DISCUSSION}

Based on the data analysis, the researcher found some findings, as follows:

a. Organization

In organization, only a few respondents $(3,3 \%)$ could write an effective introductory paragraph to address the topic and leads it into the body paragraph. They could use the outline effectively to direct the readers to the flow of their essay as well as transitional expressions. While, some few others $(76,7 \%)$ had consistent topic, introduction, and body paragraph, but are struggling in using transactional expressions to let their paragraph run smoothly. In this category, their outline was acceptable but lack of evidence made the ideas were not fully developed. The biggest error that the respondents made in organization was the order of ideas, so the organization is rarely seen $(13,3 \%)$. Some of the respondents's writing were even absence of introduction and conclusion $(6,7 \%)$.

b. Logical development of ideas

In the way of developing the ideas, no respondent was able to hit the excellent mark by the absence of unnecessary extraneous material. While a few of them $(13,3 \%)$ were able to address the topic thoroughly. Their ideas are well developed, but it could be improved though. The lack was the focus to the ideas when some unnecessary material presented in their essays. Most respondents, by percentage $73,3 \%$, did not develop the 
topic by the ideas thoroughly. It means that the ideas related to the topic were not fully explained. Some paragraphs were not divided correctly. On the other hand, only a few respondent $(13,3 \%)$ had major problems with the content. Their problem is that the ideas were inappropriate with the topic. It seems that they wrote their essay in hurry without adequate thinking towards the topic or it could be that they actually had problem in understanding the assigned task.

c. Grammar

By the data displayed in result, it seems that grammar is continuing to be an enormous problem in writing foreign language. While no respondent was able to use a correct native-like fluency of grammar, a few of them (10\%) had an advanced competence in using english grammar correctly. The grammatical errors that they made in their essay did not influence the reader's understanding toward the passage. More than half of respondents got problems in grammar that affected the content of essay negatively. There were incorrect use of relative clauses, prepositions, modals, articles, verb forms, and tense sequencing and fragments present in the essay.

d. Punctuation, spelling, and mechanic

If grammar is probably the most challenging aspect in foreign language writing, punctuation, spelling, and mechanics could be the strength of the respondents in EFL writing. Seven repondents out of thirty $(23,3 \%)$ were able to use correct English writing convention, capitals, and punctuation, and no spelling error was found. Furthermore, only a few of them had commited some errors in spelling. It seems that most of the respondents did not have any problems in punctuation.

e. Style and quality of expression

Two of thirty respondents $(6,7 \%)$ wrote an excellent paragraph with some varieties of the sentence structure, parallel structure, appropriate vocabularies in line with the context, the intention of writing, and the readers. The other six respondents, even though the word choice were not as precise as the former, but it was acceptable to convey the message of the passage. While most of them $(66,7 \%)$ misused the vocabulary, the ideas were not properly transferred to the readers. In addition, some 
sentences were too wordy and lack of variation. Two other respondents $(6,7 \%)$ completely failed in this category by using fully inappropriate vocabulary for the context.

\section{CONCLUSION}

To sum ap, almost in all five aspects of analytic writing scale, most respondents had adequate to fair competence in writing an argumentative essay, Although their competences in every aspects were almost similar, but they had strongest competence in punctuation, spelling, and mechanics of an argumentative essay as in this aspect, the respondents made the slightest error. On contrary, grammar and outlining the logical development of essay were the most challenging task for EFL college level learners in writing an argumentative essay.

\section{REFERENCES}

Baker, J, Brizee, A., Angeli, E. 2013. Argumentative Essays. Indiana: Purdue University. Retrieved from https://owl.english.purdue.edu/owl/resource/685/05

Brown, Douglas, H. 2007. Teaching by Principles: An Interactive Approach to Language Pedagogy. San Francisco. CA: Longman

Brown, Douglas, H. 2004. Language Assessment: Principle and Classroom Practice. San Francisco. CA: Longman

Creswell, John. 2003. Research Design. Lincoln: University of Nebraska

Crystal, David. 2003. English as a Global Language. Cambridge: Cambridge University Press

Harmer, Jeremy. 2007. How to Teach Writing. Harlow: Longman

Hasani, Aceng. 2016. Enhancing Argumentative Writing Skill through Contextual Teaching and Learning. Educational Research and Reviews, Vol. 22, pp. 15731578

Hedge. 2002. Approaches to Writing in EFL/ESL Context. Oxford: Oxford University Press

Linse, Caroline, T. 2005. Practical English Language Teaching for Young Learners. New York: Mc Graw-hill Companies

Nilson, Jeffrey. 1984. Writing System. Cambridge: Cambridge University Press 
Sparks, Jesse R., Song, Yi., Brantley, Wyman.,\& Liu Ou L. 2014. Assessing Written Communication in Higher Education: review and Recommendations for Next Generation Assessment (ETS Research Report Series. 14-37). Princeton: Educational Testing Service

Tidyman, Willard. 1959. Teaching the Language Arts. London: Mc Graw-hill Company 